\title{
Novel use of immunohistochemistry for phenotypic evaluation of circulating neoplastic lymphocyte populations
}

\author{
JR Finlay* ${ }^{\S}$ and KM Wyatt ${ }^{*}$ \\ ${ }^{*}$ Perth Veterinary Oncology, 305 Selby St, Osborne Park, Western Australia 6017 \\ $\checkmark$ Author for correspondence. Email: jfinlay@perthvetspecialists.com.au
}

Supplementary Figure 1. Results for polymerase chain reaction for antigen receptor rearrangement (PARR) from Case 1. Monoclonal spike consistent with expanded T cell population.

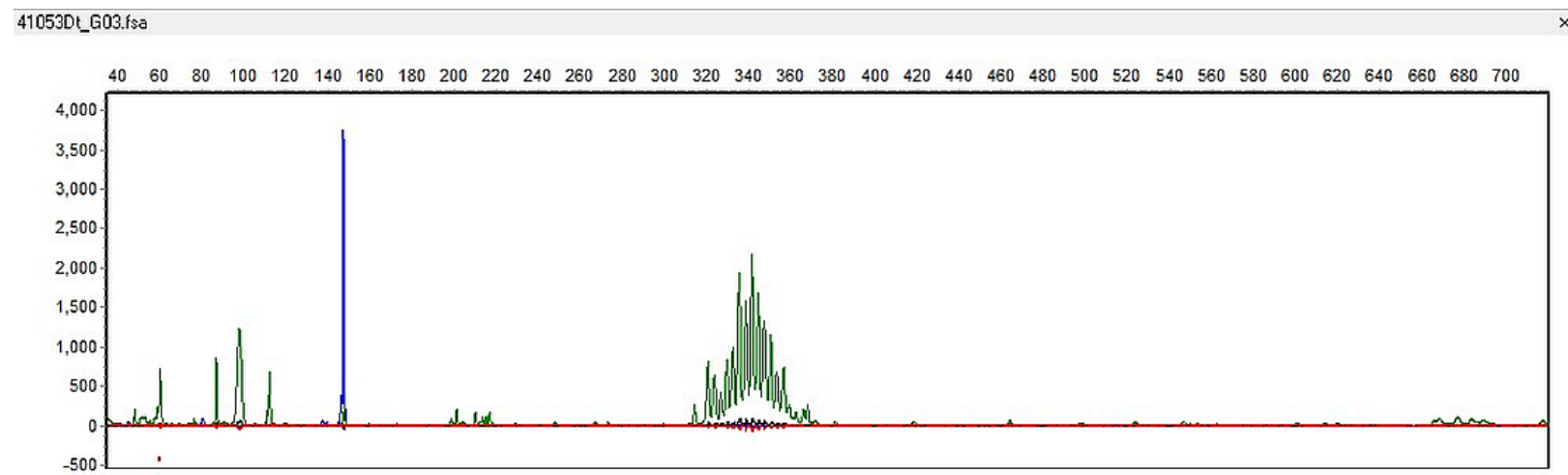

4105310_E07.isa

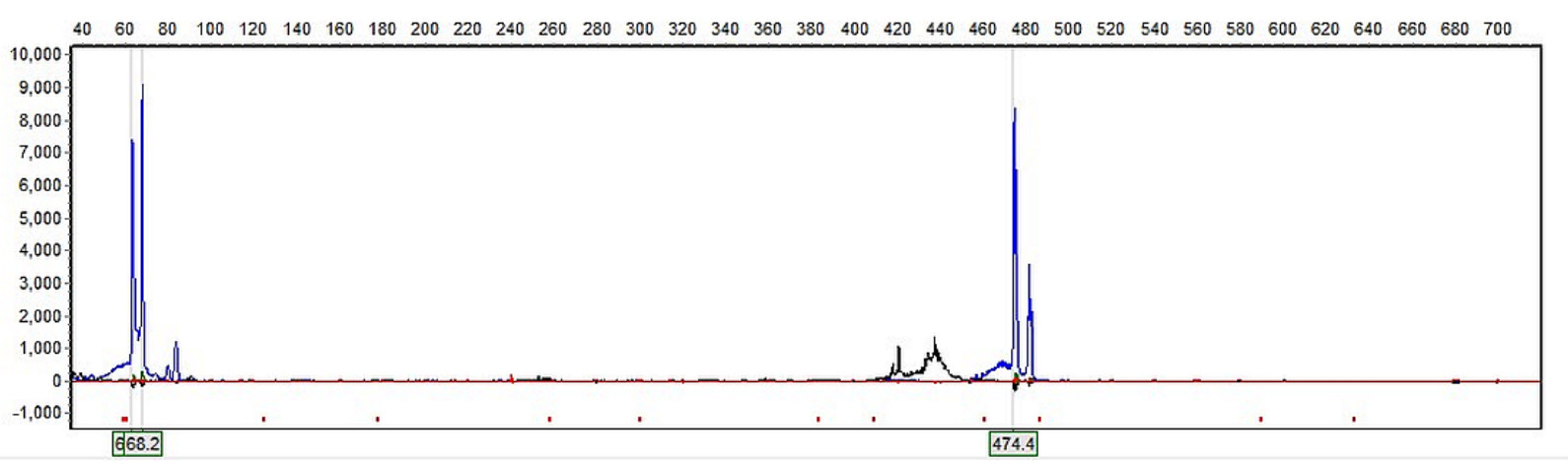

The content of this supplementary information has not been edited. All risk and liability rest with the authors. 
Supplementary Figure 2. Results for polymerase chain reaction for antigen receptor rearrangement (PARR) from Case 2. Monoclonal spike consistent with expanded T cell population.

\section{DLA02.fsa}

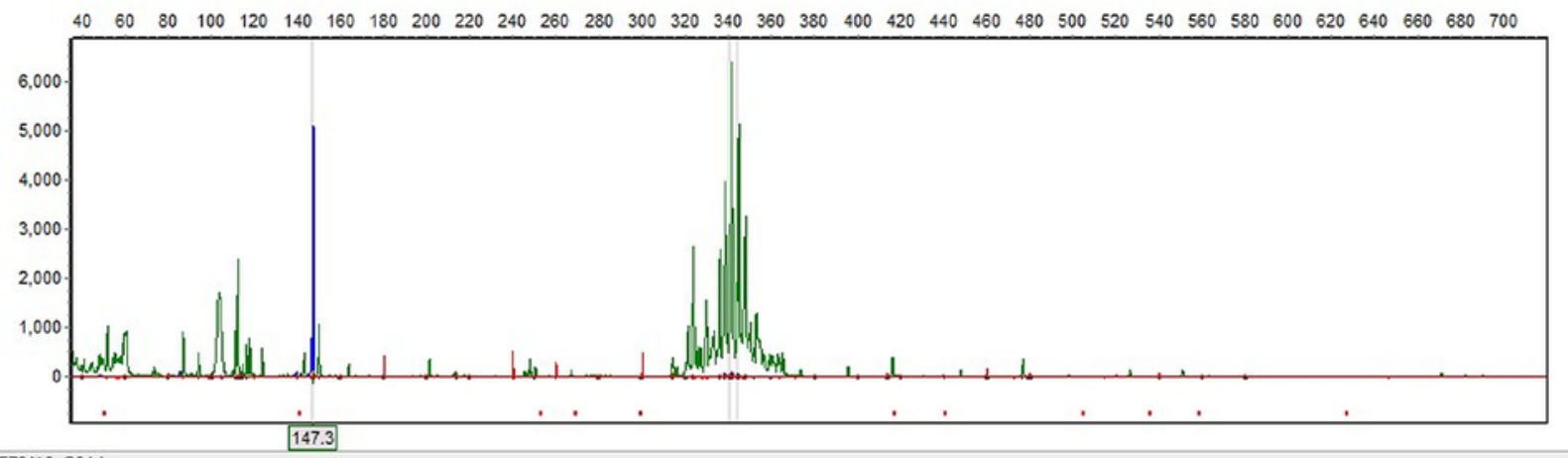

41573J10_C04.fso

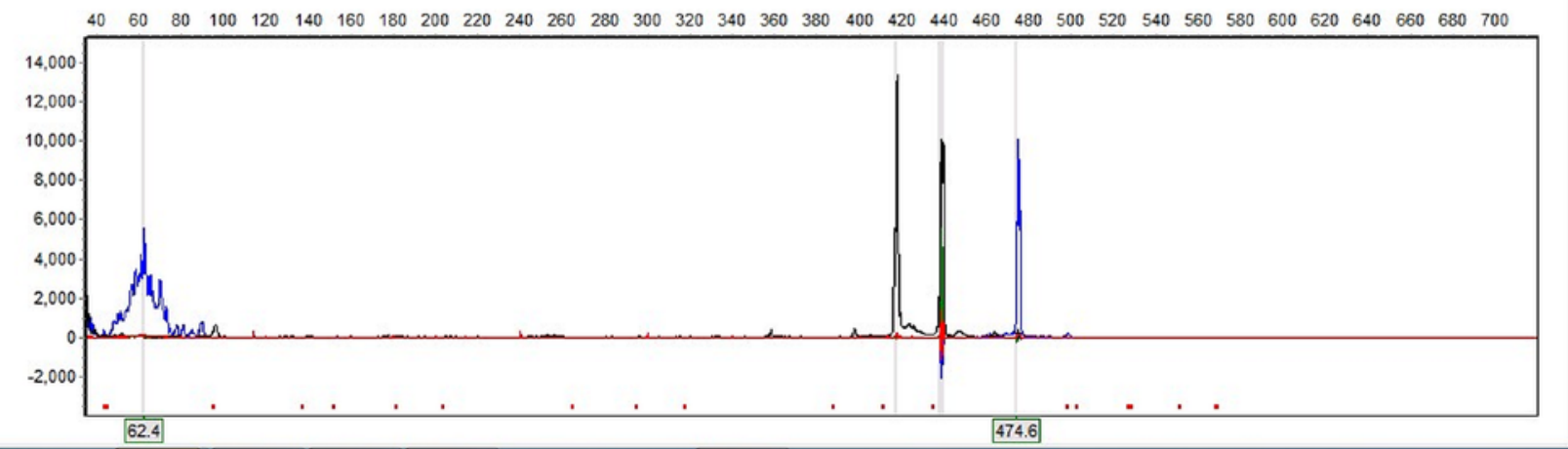

